\title{
The Relationship Between Degrees of Pre-Operative Anxiety With Pain and Post Operative Answer in Patients Who Undergo C-Section With Spinal Anesthesia
}

\author{
Boy Olifu Elniko Ginting*, Akhyar Hamonangan Nasution**, Soejat Harto** \\ *Resident ofAnaesthesiology and Intensive Therapy, Faculty of Medicine, Universitas Sumatera Utara, Medan, Indonesia \\ **Departement of Anaesthesiology and Intensive Therapy, Faculty of Medicine, Universitas Sumatera Utara, Medan, Indonesia
}

\begin{abstract}
:-
\section{$>$ Background:}

Anxiety is an unpleasant feeling that is considered a fear of a threatening danger, often the threat is unknown and always includes various emotional and hemodynamic responses experienced by the organism prior to emotional stimulation.
\end{abstract}

\section{Objective}

To determine the relationship between the degree of pre-operative anxiety with post-operative pain in patients undergoing cesarean sectio with spinal anesthesia techniques at H. Adam Malik Hospital.

\section{$>$ Method \\ Descriptive analytic research was conducted at Haji Adam Malik General Hospital in Medan from May to June 2020. The study population was all subjects scheduled to undergo sectio cesarea with spinal anesthesia at Haji Adam Malik General Hospital. The total sample obtained was 28 patients. The normal test of numerical data test was used with the Spearman Correlation test. The research hypothesis was tested using the Mann-Whitney test. In the study conducted on 28 samples divided into 2 groups, it was found that there was a moderate and direct relationship between APAIS scores and VAS scores.}

\section{Results}

Based on this study, it was found that the average preoperative APAIS score was $11.07( \pm 3.79)$. And for the mean value of postoperative VAS is $2.37( \pm 1.04)$. In the result of this study it was found that there was a moderate and unidirectional relationship to the APAIS score and this VAS score $(p<0.05)$. While the preoperative APAIS score was $11.07( \pm 3.79)$. And for the mean postoperative VAS-A value is $3.33( \pm 1.03)$. In the result of this study also found that there is a strong and direct relationship in the APAIS score and this VASA score $(\mathbf{p}<0.05)$.

\section{Conclusion}

There is a moderate and direct relationship between APAIS scores and this VAS score and that there is a strong and direct relationship in the APAIS score and this VAS-A score.

Keywords:- The Amsterdam Preoperative Anxiety and Information Scale (APAIS), Visual Analogue Scale (VAS), Visual Analog Scale for Anxiety (VAS-A)

\section{INTRODUCTION}

Anxiety is defined as an unpleasant feeling that is considered a fear of threatening danger, often the threat is unknown and always includes various emotional and hemodynamic responses experienced by the organism before the emotional stimulation. ${ }^{1}$

Pre-operative anxiety is an interesting concept in perioperative patient care. Preoperative anxiety is common in patients undergoing anesthesia and elective surgery. Even pre-operative anxiety is considered a normal response in most of these patients. The sources of pre-operative anxiety are broadly divided into two, namely anxiety about anesthetic procedures and anxiety about surgical procedures. $^{2}$

Psychological factors have been found to have a substantial impact on surgical recovery. Anxiety is very important, because it affects various aspects of the perioperative anesthesiological situation, such as preoperative visits, induction and maintenance of anesthesia, postoperative demands and physical recovery. Studies in surgical patients have identified an association between preoperative anxiety, recovery and surgical outcome. For example, postoperative pain in the recovery room can be predicted to some extent using a short questionnaire about the patient's pre-operative anxiety. ${ }^{3}$ 
The Amsterdam Preoperative Anxiety and Information Scale (APAIS) is one of the instruments used to measure pre-operative anxiety that has been validated, received and translated into various languages in the world. The APAIS instrument was first created by Moerman in 1995 in the Netherlands. APAIS aims to pre-operatively screen for anxiety and patient information needs, so that patients who need additional support can be identified. ${ }^{2}$

Among the most important documented risk factors for developing anxiety is a family history of anxiety female gender. Previous studies have described preoperative anxiety as something that can occur up to a week before the surgery, which is called physical and emotional discomfort that initially has an imminent sense of danger, which can range from lack of rest to resting state to anxiety. panic state varies according to the type of surgery, time of hospitalization and medical care expected. It is important to know the level and causes of anxiety in order to understand the patient's psychology. On the peri-operative basis, patients have anxiety related to many factors namely general concern about their health and operations, uncertainty, being away from home and family, interfering with daily routine, they also have anesthesia-related problems such as unsuccessful recovery, pain postoperative, and intraoperative awareness. ${ }^{4}$

Studies have been conducted where it has been found that the more anxiety the patient experiences before surgery, the longer the recovery period, as well as the pain he experiences during the recovery period, because this is a time that makes the patient more anxious. Elective surgery is a procedure that involves a series of fears: fear of not waking up from anesthesia, feeling pain during surgery, pain that can be caused by an invasive procedure prior to the intervention, disclosing personal information due to the effects of anesthesia or the results of the operation. Patient's own characteristics such as age, sex, patient type, previous experience or type of surgery may contribute to explain the large variability in the prevalence of postoperative pain. However, the bibliography is quite shallow in these aspects. As an anesthetist, it is very important to know the level of anxiety the patient experiences before the surgical procedure, although this procedure is difficult for many reasons, including poor quality of care in the pre-anesthesia assessment which aims to measure and classify the degree of anxiety in patients undergoing elective surgery. ${ }^{5}$
Therefore, based on the above background, the researcher wishes to assess the relationship between the degree of pre-operative anxiety and post-operative pain in patients undergoing cesarean section with spinal anesthesia techniques at H. Adam Malik General Hospital.

\section{METHODS}

This study is an analytic study with an analyticdescriptive design carried out at Haji Adam Malik General Hospital Medan. Consecutive sampling is a sample selection technique by which all subjects who come and meet the selection criteria are included in the study until the number of subjects is met. After obtaining approval from the Ethics Committee, Faculty of Medicine, University of North Sumatra, based on inclusion and exclusion criteria 27 research samples were collected. Researchers took samples by taking all patients who underwent caesarean section who were registered at the Central Surgical Installation and Emergency Surgical Installation at RSUP H Adam Malik Medan. Identification of research subjects in accordance with the predetermined criteria for acceptance and rejection. Identification of study subjects was carried out by the investigator during the pre-anesthesia visit. Informed consent was carried out by the researcher by providing an explanation of the research objectives, research procedures, potential benefits and risks in this study. If the patient states that he is willing to participate in the research, this will be documented by signing a research consent form. Patients who were unwilling to participate in the study would continue to receive the usual perioperative care and were excluded from the study. After signing the informed consent, preoperative anxiety was assessed using the APAIS score and the patient's degree of anxiety was determined at the preop visit. When the patient is in the operating room, perform peripheral venous access and monitoring. The anesthetic technique used is Regional Anesthesia Spinal Arachnoid Block (RA-SAB) with a $25 \mathrm{G}$ needle, in the L2L3 or L3-L4 area. After the procedure, the patient is taken to the recovery room and time is recorded as T0, Anxiety is again assessed using the APAIS score and pain is assessed using the VAS image table one hour after being in the recovery room, asked to the patient by showing a scale that corresponds to the perceived pain. felt by the patient. This assessment is carried out directly by researchers who are not involved in administering drugs to these patients. The results of the observational data in the two groups were compared statistically The study is terminated if the research subject refuses to participate further, the operation is prolonged so that additional general anesthesia is needed, and lifethreatening airway, heart, lung, and brain emergencies occur. 


\section{RESULTS}

This research was conducted during June 2020 at the Central Surgical Installation of the Adam Malik Center General Hospital, Medan. This study aims to determine the relationship between the degree of pre-operative anxiety with post-operative pain and anxiety in patients undergoing cesarean section with spinal anesthesia techniques. The sample obtained in this study amounted to 27 people according to inclusion and exclusion criteria.

\begin{tabular}{|c|c|c|}
\hline & Characteristic & p-value \\
\hline Age, mean $\mathbf{\pm}$ SD & $28,41 \pm 4,00$ & $0,719 \mathrm{a}$ \\
\hline Ethnic, $\mathbf{( \% )}$ & & \\
\hline Jawa & $12(44,4)$ & $0,702 \mathrm{~b}$ \\
\hline Melayu & $7(25,9)$ & \\
\hline Batak & $8(29,6)$ & $0,457 \mathrm{~b}$ \\
\hline Religion, $(\boldsymbol{\%})$ & $17(63)$ & \\
\hline Islam & $7(25,9)$ & \\
\hline Protestant & $3(11,1)$ & $0,680 \mathrm{~b}$ \\
\hline Catholic & & \\
\hline Pendidikan, $\mathbf{n}(\%)$ & $8(29,6)$ & \\
\hline Junior High School & $10(37,1)$ & \\
\hline Senior High School & $9(33,3)$ & \\
\hline Bachelor degree & $\mathbf{2 7}$ & \\
\hline Jumlah & & \\
\hline $\mathrm{a}=$ Spearman's Correlation; $\mathrm{b}=$ ANOVA & & \\
\hline
\end{tabular}

Table 1:- Demographic Data Table

In this study, the mean age of the patients was 28.41 years $( \pm 4.00)$. Based on ethnicity, it was found that the sample consisted of 12 Javanese people (44.4\%), 7 Malays (25.9\%), and 8 Batak people (29.6\%). Based on religion, it was found that 17 people were Muslim (63\%), 7 Protestants (25.9\%) and 3 Catholics (11.1\%). Based on the latest education level, it was found that the sample with the last level of education was 8 people $(29.6 \%)$, the last high school education level was 10 people $(37.1 \%)$, and the last education level sample was 9 people ). Statistically, there was no significant difference between the characteristics of the samples.

\begin{tabular}{|l|l|l|l|}
\hline & Mean $( \pm$ SD) & P value & R value \\
\hline $\begin{array}{l}\text { APAIS } \\
\text { preoperative }\end{array}$ & $11,07(3,79)$ & 0,004 & $+0,534$ \\
\cline { 1 - 2 } $\begin{array}{l}\text { VAS } \\
\text { postoperative }\end{array}$ & $2,37(1,04)$ & & \\
\hline
\end{tabular}

Table 2:- Correlation between APAIS Preoperative Score and Postoperative VAS

*Spearman's Correlation

It was found that the mean preoperative APAIS score was $11.07( \pm 3.79)$. And for the postoperative VAS mean value was $2.37( \pm 1.04)$. Statistically there is a significant relationship between the APAIS score and the postoperative VAS score with a $\mathrm{p}$ value of 0.004 . The correlation value is +0.534 , which means that there is a moderate and unidirectional relationship between the APAIS score and this VAS score.

\begin{tabular}{|c|c|c|c|}
\hline & Mean $( \pm$ SD) & P value & R value \\
\hline $\begin{array}{c}\text { APAIS } \\
\text { preoperative }\end{array}$ & $11,07(3,79)$ & 0,001 & $+0,787$ \\
\cline { 1 - 2 } $\begin{array}{c}\text { VAS-A } \\
\text { postoperative }\end{array}$ & $3,33(1,04)$ & & \\
\hline
\end{tabular}

Table 3:- Correlation between Preoperative APAIS Score and Postoperative VAS-A
$*$ Spearman's Correlation

It was found that the mean preoperative APAIS score was $11.07( \pm 3.79)$. And for the postoperative VAS-A mean value was $3.33( \pm 1.03)$. Statistically there is a significant relationship between the APAIS score and the postoperative VAS-A score with a $\mathrm{p}$ value of 0.001 . The correlation value is + 0.787, which means that there is a strong and unidirectional relationship between the APAIS score and this VAS-A score.

\section{CONCLUSIONS}

There was a significant relationship between the APAIS score and the postoperative VAS score with a $\mathrm{p}$ value of 0.004 and an $r$ value of +0.534 , which means that there is a moderate and unidirectional relationship between the APAIS score and this VAS value.It was found that the mean preoperative APAIS score was $11.07( \pm 3.79)$. It was found that the mean postoperative VAS value was 2.37 ( \pm 1.04) 
Statistically there is a significant relationship between the APAIS score and the postoperative VAS-A score with a $p$ value of 0.001 . The correlation value is +0.787 , which means that there is a strong and unidirectional relationship between the APAIS score and the VAS-A score.

\section{REFERENCES}

[1]. Leung AY. Postoperative Pain Management in Obstetric Anesthesia-New Challenges and Solutions. $J$ Clin Anesth 2004 Feb;16(1):57-65.

[2]. Sommer M, de Rijke JM, van Kleef M, Kessels AG, Peters ML, GeurtsJW et al. The prevalence of postoperative pain in a sample of 1490 surgical inpatient. Eur J Anaesthesiol, 2008; 25: 267-74

[3]. Misiolek H, Cettler M, Woron J, et al. The 2014 Guidelines For Post- Operative Pain Management. 2014.

[4]. Apfelbaum JL, Chen C, Mehta SS, Gan TJ. Postoperative pain experience: results from a national survey suggest postoperative pain continuous to be undermanaged. Anest Analg, 2013; 97: 534-40

[5]. Larkin R.. Acute pain management ; scientific evidence. National Health and Medical Research Council.Commonwealth of Australia. 2019.pp.1-8 